Горбань Владимир Сергеевич

кандидат юридических наук, старший научный сотрудник сектора философии права, истории и теории государства и права Института государства и права РАН

\section{ЗАЧЕМ ФИЛОСОФИЯ ПРАВА СЕГОДНЯ?}

\section{Аннотация:}

В статье исследуется проблема проявления и преодоления некоторых кризисных симптомов современной философии права, обусловливающих существенную девальвацию философии права как целостного знания о праве и справедливости в их сущностной трактовке. На основе анализа преимущественно зарубежной правовой литературы описываются и раскрываются различные факторы и тенденции, оказывающие влияние на характер современного философско-правового знания и обоснование его социокультурной ценности. К числу таких факторов относятся: партикуляризация правовых знаний; изменение интерпретационной парадигмы; отказ от традиционных подходов и ракурсов философии права; девальвация идеи справедливости в различных версиях новых концепций о праве (системной теории, экономического анализа и m. п.); «прогрессирующая эрозия права» и др. В качестве перспективного направления философско-правовой трактовки права рассматривается обоснование его как воплощенного требования законной справедливости.

Ключевые слова:

философия права, целостное знание, справедливость, право, закон, партикуляризация знания, прагматизм, эрозия права, законная справедливость.

\section{Gorban Vladimir Sergeevich}

PhD in Law, Senior Research Fellow, Sector of Legal Philosophy, History and Theory of State and Law, Institute of State and Law, Russian Academy of Sciences

\section{WHY DO WE NEED THE PHILOSOPHY OF LAW TODAY?}

\begin{abstract}
Summary:
The paper discusses several crisis symptoms of the modern philosophy of law leading to a significant devaluation of the legal philosophy as a holistic knowledge of law and justice in their interpretation and reviews the ways to overcome these symptoms. Based on the analysis of predominantly foreign legal literature, the research describes and identifies various factors and trends influencing the nature of contemporary philosophical and legal knowledge and the substantiation of its social and cultural value. These factors include the particularism of legal knowledge; changes in the interpretive paradigm; rejection of traditional approaches and perspectives in the philosophy of law; devaluation of the idea of justice in many versions of the new concepts of law (systemic theory, economic analysis); progressive erosion of law. The substantiation of law as the embodied requirement of legal justice is regarded as the promising area of the philosophical and legal interpretation of the law.
\end{abstract}

Keywords: philosophy of law, holistic knowledge, justice, right, law, particularism of knowledge, pragmatism, erosion of law, legal justice.

В основе предлагаемого исследования лежит тезис о том, что в современной, распространенной как в российских, так и зарубежных дискуссиях и рассуждениях о праве практике обращения к поиску ответов на традиционные вопросы философии права систематически проявляются попытки девальвации целостного знания и его социокультурной ценности. Философия права очередной раз в своей истории подвергается воздействию такого рода факторов, которые заставляют вновь говорить о потребности в восстановлении дисциплинарного значения и статуса фрилософии права. Философия права по самой своей сути всегда ценностно-ориентированна. Она есть «вечный процесс познания, который задействуется в ходе критического осмысления справедливости» [1, S. 45]. Однако именно это обстоятельство и делает ее непопулярной в современной парадигме социогуманитарного знания, в которой часто артикулируется отказ от традиционных принципов и ракурсов познания в угоду партикуляризации и утилитаризации знаний, нужной, но зачастую чрезмерной их социологизации, логике системных и экономических теорий и, как следствие, антиисторического знания.

Так, например, в современной интерпретационной парадигме восхождение к авторскому смыслу текстов, сорормулированных тем или иным мыслителем правовых и политических идей рассматривается зачастую как избыточное, а тексты либо подвергаются объективно-структурной реконструкции (в лучшем случае), либо вовсе рассматриваются как набор культурных цитат и семиотических объектов. В связи с этим ссылка на оригинальный смысл и авторство часто рассматривается как излишняя, а интерпретатор, реконструирующий ту или иную правовую идею, разрабатывает авторский текст таким образом, что уже сам процесс интерпретации рассматривается как творческий, направленный на «создание» смысла, для задействования которого достаточно взять за основу те или иные схематизированные цитаты. Можно привести частный пример одного из недавних крупных научных форумов правоведов, который состоялся в Бонне (Гер- 
мания) осенью 2018 г. В докладах представителей разных стран (всего 48) зачастую воспроизводились теоретические и практически ориентированные конструкты, которые представлялись как «новые», однако, по сути, во многих из них речь шла лишь об аппликации классических политикоправовых идей к конкретным областям правовой науки (например, о поиске универсальной догматики уголовного права, но в действительности с позиции социологии М. Вебера, или интерпретации как «новой» сквозной для юридической науки темы - право как сила) [2].

Другой, не менее важный ракурс проблемы философии права обнаруживается при изучении российской и зарубежной философско-правовой и юридической литературы по вопросу о справедливости, а также различении права и закона. Вплоть до середины XX в. эти темы в тех или иных трактовках и исполнениях являлись лейтмотивов всех концепций философии права [3]. После Второй мировой войны появились специфические версии философий права, в которых с какой-то удивительной непочтительностью идея справедливости объявляется бессмысленной (так называемые системные теории права) или объясняется исключительно в экономическом контексте (теория экономического анализа права). Появляются призывы партикуляризировать философию права на множество отдельных отраслевых философий права - фрилософия уголовного права, фрилософия гражданского права и т. п., в которых философия ставится в подчиненное положение по отношению к догматической части соответствующей правовой науки.

Авторитет традиционных вопросов философии права, в частности о познании права в связи со справедливостью, все чаще сужается до состояния, когда в этом видится лишь дань прошлому. Если юридический позитивизм оправдывал свою теоретическую идентичность как оппозицию к теориям, обосновывающим право категорией справедливости, то сегодня получают хождение такие теории, которые вообще порывают со всякой традицией и пытаются проложить себе собственную дорогу. К последним относятся так называемая системная теория права; теория экономического анализа права; теория права в обществе повышенных рисков. Они ориентируются не на традиционные трактовки и критерии познания права, а на так называемые метатеории общенаучного, социально-научного или экономического контекста, из которых следуют суждения о применимости соответствующих категорий для сферы права. К примеру, системная (функциональная) теория Н. Лумана оперирует понятием общества как автономной системы, в которой право является одной из подсистем. Право рассматривается также как саморегулируемая система, в которой индивидуум представляет лишь определенную функцию системы. Справедливость объявляется в системной теории как бессмысленная категория [4].

По замыслу Н. Лумана, не имеется никаких масштабов и критериев правильности вне саму себя устанавливающей и аутопоэтически воспроизводящей системы позитивного права. Всякое содержательное представление о справедливости с точки зрения системной теории не имеет никакого эффекта. Способность воспроизведения правовой системы устроена на том, что также несправедливые, но формально правомерные решения рассматривают как действующие. Принимаемое большинством голосов согласие или даже консенсус не требуются согласно системной теории для действия правовых суждений и даже являются контрпродуктивными, поскольку сдерживают развитие правовой системы.

Появление новых концепций, несмотря на то что они имеют определенное хождение, отнюдь никак не упраздняет и не отменяет традиционных вопросов философии права, в частности о соотношении, разграничении права и закона. Попытки девальвировать значение самих вопросов вместо поиска ответов на них приводят лишь к осознанию, иногда, как показывает история, очень горькому, необходимости все же ответить на вопросы философии права или по крайней мере приблизиться к получению искомых ответов.

Весьма показательны в связи с этим те пояснения значения фрилософии права, которые приводились немецким правоведом Э. Фехнером в предисловии к его работе «Философия права: социология и метафизика права», которая впервые была опубликована в 1956 г. «Широко распространенное недоразумение в отношении задачи философии права, - писал Э. Фехнер, - возникло в период после Второй мировой войны. Фашизм пережил крах, притом такой, какой невозможно было себе представить. Несмотря на относительно короткое время его господства, он вызвал глубокие перемены в государственном устройстве и правопорядке. Крах поэтому захватил обе эти сфреры. Многочисленные законы и инструкции были отменены и оказались неприменимыми. На широком пространстве возникли правовые пустоты, которые требовали нового порядка с самого основания. Разрушен, искажен или оказался в забвении даже сам эталон для этого. Это привело к призыву естественного права, которое поднялось как феникс из пепла позитивизма и пережило “возрождение”, которое прежде невозможно было представить. С ним философия права (стержнем которой является учение о естественном праве) приобрела новое значение» [5, S. 3].

Но уже в октябре 1970 г. в Германии в Фрайбурге состоялось заседание немецкой секции международной ассоциации социальной и правовой философии под названием «Для чего фрилософия права сегодня?». В 1976 г. вышла книга известного немецкого правоведа Германа Кленера под названием «Философия права в кризисе» [6]. 
Как говорил Р. Иеринг, уж слишком часто и так легко мы забываем, какой ценой и какими усилиями были добыты те простые истины, что человек как таковой свободен, что военный плен не обусловливает рабства, что государство - нечто большее, чем просто сумма индивидов, и что главная задача его - осуществлять право и справедливость до максимально возможных пределов [7].

Лучшей иллюстрацией настоящей роли философии права являются некоторые судебные решения немецких судов, которые выносились сразу после Второй мировой войны. Так, в решении от 13 ноября 1945 г. участкового суда Висбадена говорилось: «Безвозмездная экспроприация еврейской собственности на основе законов, изданных в период господства национал-социалистического права, объявляется противоправной». При этом в качестве аргументов приводились следующие соображения: «Согласно учению о естественном праве существуют права человека, которые государство своим законодательством не может отменить. Это такие права, которые с природой и сущностью человека так тесно связаны, что вместе с их отменой была бы уничтожена духовно-нравственная природа человека... Законы, которыми собственность евреев объявлялась перешедшей государству, противоречат, таким образом, естественному праву и являются уже ко времени их издания ничтожными» [8, S. 36].

За этим решением последовали и многие другие, которые также ссылались на естественное право. Как писали в немецкой литературе, наступила пора «ренессанса естественного права».

Весьма заметными в наши дни становятся попытки диверсификации традиционных теоретико-методологических практик построения фрлософрско-правовых концепций и знаний, замены их суррогатными формулами, акцентирующими внимание не на целостности картины познания, понимания и истолкования права как сущности и явления, а на специфической, зачастую чрезмерно социологизируемой морфологии права как многомерного явления (не сущности!), детерминируемого бесконечным множеством фрорм социальности. Вследствие этого происходит размывание онтологического статуса (позитивного) права. Ярким примером является тема так называемого «мягкого права», инспирированная пришедшей из американского права и практики международных соглашений понятийной формулой soft law, которая зачастую сознательно даже не переводится на национальные языки, поскольку, очевидно, почти сразу проявляется конфликт традиционных подходов понимания права и специфического явления лишь отдельной культуры правового мышления. В данном случае определенный способ (далеко не всегда строго) правового дисциплинирования участников правового общения выдается за некий самобытный тип или вид права, который оценивается как таковой лишь по статистически достигаемым результатам, но не по сути.

Другим примером является легкообнаруживаемая тенденция интерпретации правопознания с помощью методологии прагматизма или ее отдельных элементов, согласно которой, по версии одного из основных разработчиков этого направления У. Джеймса, функция философии состоит в уяснении того, какая разница для меня и для вас, если та, а не иная модель мира является истинной. Соответственно, «реконструкция фрилософии» в смысле прагматизма предполагает отказ от изучения основ бытия и познания в пользу отработки методов разрешения разнообразных проблемных ситуаций жизни. Согласно У. Джеймсу, «в качестве истины, которая может быть принята, прагматизм признает лишь одно то, что наилучшим образом руководит нами, что лучше всего приспособлено к любой части жизни и позволяет лучше всего слиться со всей совокупностью опыта» [9, р. 37]. Соответственно, «...гипотеза о Боге истинна, если она служит удовлетворительно...» [10, р. 37]. В связи с этим, оценивая прагматизм, Б. Рассел писал следующее: «Во всем этом я чувствую серьезную опасность, опасность того, что можно назвать "космической непочтительностью". Понятие "истины” как чего-то зависящего от фактов, в значительной степени не поддающихся человеческому контролю, было одним из способов, с помощью которых фрилософия до сих пор внедряла необходимый элемент скромности. Если это ограничение гордости снято, то делается дальнейший шаг по пути к определенному виду сумасшествия - к отравлению властью, ...к которому тяготеют современные люди - фрилософы и нефилософы. Я убежден, - продолжал Б. Рассел, - что это отравление является самой сильной опасностью нашего времени и что всякая философия, даже ненамеренно поддерживающая его, увеличивает опасность громадных социальных катастроф» [11, р. 289; 12, с. 793].

Наконец, кризис фрилософско-правовых и юридических знаний обусловливается таким явлением, которое можно назвать «прогрессирующая эрозия права» (Й. Гниза об отношении к праву в Германии). Следует обратить внимание на постоянно проявляющиеся варианты искажения смысла закона и законности в политико-правовых практиках и теоретических интерпретациях. Особенно наглядным примером являются так называемые «законы о санкциях» в практике США и ряда европейских государств, грубо и произвольно попирающие принцип государственного суверенитета других стран. Сюда же можно отнести специфическое явление, наблюдаемое сегодня в некоторых европейских странах, которое можно назвать «конформистской законностью», когда даже самые грубые фрормы нарушения гарантированных законом прав и свобод человека (включая неоднократные убийства, изнасилования, регулярные нападения, сопровожда- 
ющиеся причинением вреда здоровью граждан, и т. п.), правил поведения в обществе и цивилизованного общения игнорируются политическими элитами и правоохранительной системой ради некоторой иллюзорной формы социального мира, постоянно балансирующего между социальными протестами и политической недальновидностью (называемой толерантностью), сопряженной с искусственным сдерживанием режима законности для кажущейся минимизации социальных волнений («прогрессирующая эрозия права» Й. Гниза).

В 2017 г. председатель союза судей Германии Й. Гниза выпустил книгу под названием «Конец справедливости: судья бьет тревогу» [13]. Автор называет более 20 различных симптомов крайне пренебрежительного отношения к праву в Германии, в первую очередь со стороны политиков, которые, по мнению автора, грозят катастрофой для правового государства. «Не только беспомощность, но и непонимание, возможно даже отказ, - сетует Й. Гниза, - характеризуют обращение наших политиков с правом. Если это необходимо, они придают ему такую фрорму, которая позволяет им использовать его в данный момент» [14, S. 12]. «Для меня не существует никаких сомнений в том, что опорный столб нашего общественного порядка - правовое государство - находится в опасности» [15, S. 16]. «Право не означает справедливость автоматически, так как в первую очередь оно является системой порядка, которая стремится к установлению баланса - между различными сторонами и разнообразными правовыми благами. Однако эта система функционирует только в том случае, если справедливость в смысле юстиции не смешивается с моралью» [16].

Подчеркивая, что право, в отличие от морали, обеспечивает стабильность и прочность социального порядка, этот автор критикует целенаправленное использование моральных аргументов как обусловленных духом времени и необязательных для подмены права, когда, например, эмоциональные оценки сознательно задействуются в средствах массовой информации для принятия сиюминутного (под влиянием морального давления общественности), а не строго правового решения. «Суды объединяются, места сокращаются, снижается число судей и их вспомогательного персонала, сидящих за требующими ремонта фрасадами, которые впечатляюще демонстрируют наружу состояние немецкого правового государства» [17]. Автор приводит данные о том, что в настоящее время судебный корпус нуждается в 2000 судей и прокуроров [18, S. 138].

Рассуждения и жалобы немецкого судьи Й. Гнизы, который приводит множество примеров пренебрежения правом в его стране, грозящих, по его мнению, даже разрушением правового государства как модели устройства и существования общества, по существу, сводятся к тому, что в различных сферах пренебрежение правом, искажение закона и законности в силу политической халатности или сиюминутной политической целесообразности создают условия для того, чтобы на место обеспечиваемой правом, господством права и практикой законности социальной стабильности и защищенности заступали различные формы произвола и насилия. Примечательно при этом то обстоятельство в понимании соотношения права и справедливости в рассуждениях этого автора, что справедливость понимается им как результат действия права, как правовое требование, осуществляемое и реализуемое посредством применения закона при разрешении конкретных судебных дел. Иными словами, как некая форма законной справедливости в судебном решении.

В одной из недавних дискуссий в ходе телевизионной передачи на телеканале «Культура» (2014) о том, как правовые доктрины определяют нашу жизнь, известным правоведом, историком права В.Г. Графрским была высказана мысль о том, что в нашем современном правопонимании желаемой и обоснованной является трактовка права как «результата требований законной справедливости», что созвучно со словом «правда», и в этом контексте речь идет о некоторой ориентации правопонимания на фрормулу «правоискательства». При этом право в этом смысле, т. е. осуществленного требования законной справедливости, является «пределом насилию и произволу».

Проведенный анализ некоторых симптомов девальвации философско-правовых знаний позволяет сделать вывод, что в современных условиях тенденциозной партикуляризации научного знания и диверсификации ряда его сфер, множащихся попыток найти точку опоры вне традиционных, классических парадигм и установок (прагматизм, функциональная социология, концепция «открытого общества», юриметрические подходы, «эрозия права» и т. п.) все более ощущается потребность в целостном философско-правовом знании. Речь, конечно же, не идет о единстве разнообразных философско-правовых концепций и трактовок права, которое было бы еще более губительным для философии права как таковой. С оттенком единства можно было бы говорить только о давнем стремлении мыслителей к универсализации знаний, а точнее - о поиске фрормулы такой универсализации. Целостность знания понимается в том смысле, который раскрывается через взаимосвязанную характеристику права как сущности (в единстве познаваемого объекта) и права как явления (во всем многообразии проявления его сущности). В связи с этим та или иная концепция именно философии права лишь уточняет, дополняет, расширяет и развивает совокупное и целостное, но одновременно многомерное знание о праве, а не отрицает его и не подменяет суррогатными формулами. 


\section{Ссылки:}

1. Kunz K.-L., Mona M. Rechtsphilosophie, Rechtstheorie, Rechtssoziologie: eine Einführung in die theoretischen Grundlagen der Rechtswissenschaft. 2., neu bearbeitete und ergänzte Aufl. Bern ; Stuttgart ; Wien, 2015. XII, 287 S.

2. 8. Bonner Humboldt-Preisträger-Forum „Zwischen Handwerk und Bekenntnis, Empirie und Normativität: Selbstbestimmung der internationalen Rechtswissenschaft", 17.10.2018 - 21.10.2018. Bonn, 2018.

3. Графский В.Г. Власть законов: история идеи и современность // Политико-правовые ценности: история и современность / под ред. В.С. Нерсесянца. М., 2000. 256 с. ; Его же. Проблема взаимоотношений власти и знания в истории политической мысли : дис. ... д-ра юрид. наук. М., 1992. 350 с. ; Нерсесянц В.С. Право и закон. Из истории правовых учений. М., 1983. 366 с.

4. Büllesbach A. Systemtheorie im Recht // Einführung in Rechtsphilosophie und Rechtstheorie der Gegenwart / hrsg. von A. Kaufmann, W. Hassemer, U. Neumann. 8. Aufl. Heidelberg, 2011. S. 428-457 ; Luhmann N. Die Rückgabe des zwölften Kamels: Zum Sinn einer soziologischen Analyse des Rechts // Zeitschrift für Rechtssoziologie. 2000. Vol. 21, iss. 1. S. 3-60. https://doi.org/10.1515/zfrs-2000-0103.

5. Fechner E. Rechtsphilosophie: Soziologie und Metaphysik des Rechts. 2. unveränd. Aufl. Tübingen, 1962. XX, 303 S.

6. Klenner H. Rechtsphilosophie in der Krise. Berlin, 1976. $180 \mathrm{~S}$

7. Jhering R. Geist des römischen Rechts auf den verschiedenen Stufen seiner Entwicklung. Th. 1. 2. verb. Aufl. Leipzig, 1866. $\mathrm{XIV}, 361 \mathrm{~S}$.

8. Süddt. Juristenzeitung. 1946. S. 36.

9. James W. Pragmatism: A New Name for Some Old Ways of Thinking: Popular Lectures on Philosophy. L., 1908. XII, 308 p.

10. Ibid. P. 37.

11. Ibid. P. 289

12. Новейший философский словарь. Изд. 2-е, перераб. и доп. Минск, 2001. 280 с.

13. Gnisa J. Das Ende der Gerechtigkeit: ein Richter schlägt Alarm. Freiburg im Breisgau, 2017. 288 S

14. Ibid. S. 12

15. Ibid. S. 16

16. Ibid.

17. Ibid.

18. Ibid. S. 138 .

\section{References:}

8. Bonner Humboldt-Preisträger-Forum „Zwischen Handwerk und Bekenntnis, Empirie und Normativität: Selbstbestimmung der internationalen Rechtswissenschaft", 17.10.2018 - 21.10.2018 2018, Bonn, (in German).

Büllesbach, A 2011, 'Systemtheorie im Recht', in A Kaufmann, W Hassemer \& U Neumann (hrsg.), Einführung in Rechtsphilosophie und Rechtstheorie der Gegenwart, 8. Aufl., Heidelberg, S. 428-457, (in German).

Fechner, E 1962, Rechtsphilosophie: Soziologie und Metaphysik des Rechts, 2. unveränd. Aufl., Tübingen, XX, 303 S., (in German).

Gnisa, J 2017, Das Ende der Gerechtigkeit: ein Richter schlägt Alarm, Freiburg im Breisgau, S. 12, 16, 138, (in German). Grafsky, VG 1992, The Problem of the Relationship between Power and Knowledge in the History of Political Thought, D.Phil. thesis, Moscow, 350 p., (in Russian).

Grafsky, VG 2000, 'The Power of Laws: the History of Ideas and Modernity', in VS Nersesyants (ed.), Politiko-pravovyye tsennosti: istoriya i sovremennost', Moscow, 256 p., (in Russian).

James, W 1908, Pragmatism: A New Name for Some Old Ways of Thinking: Popular Lectures on Philosophy, London, XII, pp. 37,289

Jhering, R 1866, Geist des römischen Rechts auf den verschiedenen Stufen seiner Entwicklung, Th. 1, 2. verb. Aufl., Leipzig, XIV, 361 S., (in German).

Klenner, H 1976, Rechtsphilosophie in der Krise, Berlin, 180 S., (in German).

Kunz, K-L \& Mona, M 2015, Rechtsphilosophie, Rechtstheorie, Rechtssoziologie: eine Einführung in die theoretischen Grundlagen der Rechtswissenschaft, 2., neu bearbeitete und ergänzte Aufl., Bern, Stuttgart, Wien, XII, 287 S., (in German).

Luhmann, N 2000, 'Die Rückgabe des zwölften Kamels: Zum Sinn einer soziologischen Analyse des Rechts', Zeitschrift für Rechtssoziologie, vol. 21, iss. 1, S. 3-60. https://doi.org/10.1515/zfrs-2000-0103.

Nersesyants, VS 1983, Right and Law. Glimpses of History of Legal Doctrines, Moscow, 366 p., (in Russian).

Süddt. Juristenzeitung 1946, S. 36., (in German).

The Newest Philosophical Dictionary 2011, 2nd, Minsk, 280 p., (in Russian). 